caused hypocontractile myocardium, a similar phenomenon was observed. The effect of an additional potassium or magnesium ion infusion when intracellular calcium concentration began to increase was not assessed, ${ }^{2}$ and the assertion that an extra potassium infusion is counterproductive must be treated as speculative. Menasche et al. ${ }^{3}$ and Lessana et al. ${ }^{4}$ reported their observation during warm blood cardioplegia, but did not address the issue of using magnesium, a calcium antagonist, to treat incomplete myocardial arrest. Actually, Menasche et al. reported the prompt extermination of returning electromechanical activity by increasing the potassium concentration of the cardioplegia. $^{3}$

In our article, the contribution of renal insufficiency and the effect of potassium sparing diuretics on the ultimate hyperkalaemia was mentioned, and haemofiltration during cardiopulmonary bypass was recommended. We appreciate that Drs. Yam, Fox and Fabri agree.

We agree that blood chemistry profiles such as arterial blood gas analysis and electrolyte concentration must be monitored closely during cardiopulmonary bypass. Following a hyperkalaemia experience, we have reduced the time between blood chemistry profiles to $30 \mathrm{~min}$.

In conclusion, we agree with Drs. Yam, Fox and Fabri that careful selection of cardioplegia infusion, close monitoring of the patient's blood chemistry profile and timely therapeutic management are essential for optimal patient care.

Y. James Kao PhD MD

Department of Anesthesiology

University of California Irvine Medical Center

Gabor B. Racz MB ChB

Texas Tech University Health Sciences Center

REFERENCES

1 Kao Y, Mian T, Kleinman S, Racz GB. Hyperkalaemia: a complication of warm heart surgery. Can J Anaesth 1993; 40: 67-70.

2 Steenbergen C, Murphy E, Watts J, London R. Correlation between cytosolic free calcium, contracture, ATP, and irreversible ischemic injury in perfused rat heart. Circ Res 1990; 66: 135-46.

3 Menasche P, Peynet J, Touchout B, et al. Normothermic cardioplegia: is aortic cross-clamping still synonymous with myocardial ischaemia? Ann Thorac Surg 1992; 54: 472-8.

4 Lessana A, Romano $M$, Singh A, et al. Beyond cold cardioplegia. Ann Thorac Surg 1992; 53: 666-9.

\section{Laryngeal mask airway: defining the limits}

To the Editor:

The letter from Williams and Bailey entitled "Management of failed oral fibreoptic intubation with LMA insertion under topical anaesthesia"' raises questions about standards of care. That the LMA can be inserted in the awake patient is valuable information. However, the de- tails of the case deserve some scrutiny. Guidelines for the use of the LMA have been elucidated by Fisher $e t$ $a l^{2}$ Among the conditions said to be unsuitable for management with the LMA were aspiration risk and difficult airway access: both existed in the case presented.

While many anaesthetists have used the LMA for nasal surgery without problems, the theoretical concern of aspiration remains. The LMA offers no protection from reflux of gastric contents. ${ }^{3}$ This would include blood and irrigation fluid "swallowed" during nasal surgery even in the presence of a throat pack. A reference was cited supporting the ability of the LMA to prevent dye placed in the mouth from entering the larynx. ${ }^{4}$ However, in this study, using only $10 \mathrm{ml}$ of $0.1 \%$ methylene blue, there was a "minimal leak" in 4 of 64 patients, and a small pool of dye within the mask in one patient whose mask had been partially displaced during draping. No mention was made of examination of the esophagus for dye. In addition, cases of severe aspiration during LMA anaesthesia have been published. ${ }^{5}$ It is our opinion that, until controlled clinical trials have demonstrated the safety of using the LMA in this clinical setting, a conservative approach should be adopted.

It seems unwise for a patient, who has already presented an impossible intubation, to undergo general anaesthesia with the LMA for elective surgery. Should the need for urgent intubation arise, direct tracheal access from the neck may be impossible. If this case could not have been done under local anaesthesia, awake blind or fibreoptic intubation through LMA would have been a safe and relatively easy option.

The LMA is an ingenious device of great utility and popularity. Unfortunately, the practical importance of its theoretical risks has not yet been determined. Again, until specific, controlled clinical trials examining large populations, have been published, we advocate a conservative approach based on these theoretical concerns.

Joanne Todesco MD FRCPC

Colin Dodd MD FRCPC

R. Tudor Williams MRCS LRCP FRCPC

Department of Anaesthseia

Foothills Hospital

University of Calgary

\section{REFERENCES}

1 Williams PJ, Bailey PM. Management of failed oral fibreoptic intubation with laryngeal mask airway insertion under topical anaesthesia (Letter). Can J Anaesth 1993; 40: 287.

2 Fisher JA, Ananthanaryan C, Edelist G. Role of the laryngeal mask in airway management. Can J Anaesth 1992; 39: 1-3 
3 Brain AIJ. The Intravent Laryngeal Mask. Instruction Manual. 1990.

4 John RE, Hill S, Hughes TJ. Airway protection by the laryngeal mask. Anaesthesia 1991; 46: 366-7.

5 Nanji GM. Maltby JR. Vomiting and aspiration peumonitis with the laryngeal mask airway. Can J Anaesth 1992; 39: 69-70.

\section{REPLY}

Thank you for the opportunity of replying to Todesco et al.'s comments about our use of the Laryngeal Mask Airway (LMA) for nasal polypectomy and antral washout after failed awake fibreoptic intubation.

They unfortunately appear to misquote Fisher et al.'s' editorial on two important points. Firstly, "risk of aspiration" refers to aspiration of the contents of the gastro-intestinal tract. Ours was an elective, fasted patient, with no history of oesophageal reflux. We use a $176 \mathrm{~cm} \times 9 \mathrm{~cm}$ gauze throat pack and aim to fill the oropharynx and occlude the pharyngeal isthmus so that blood and irrigation fluid remain in and are aspirated promptly from the nasal cavities. We find on removal, the pack is only lightly blood stained with minimal change in weight (research in progress) and believe the chance of blood and irrigation fluid entering the oesophagus must thus be very small.

We have used the reinforced LMA for elective adenotonsillectomy ${ }^{2}$ and found that the $L M A$ protected the larynx from contamination with blood during surgery on the upper airway, in contrast to the tracheal tube, where aspiration occurred in $54 \%$ of children. Furthermore, during recovery from anaesthesia $91 \%$ of patients in the LMA group required suction to clear blood pooling in the mouth, compared with $66 \%$ in the Guedel airway group. This suggests that the LMA prevents blood from being swallowed or aspirated by the patient.

Secondly, in cases of difficult airway access, Fisher et al. state that the LMA is contra-indicated in patients whose tracheas are known to be difficult to intubate and whose lungs are difficult to ventilate. Our patient had no respiratory dysfunction, despite having ankylosing spondylitis. The LMA has been successfully used in cases of difficult intubation, ${ }^{3}$ including repair of cleft palate in an infant with Pierre Robiss syndrome, and has been advocated as a guide to aid blint tracheal intubation in cases of difficult direct laryngascopy. ${ }^{5}$

As Todesco et al. state, the LMA can be used to guide a tracheal tube blindly or under fibreoptic guidance into the trachea; and these are the methods we would hove used in the unlikely event of urgent tracheal intubation being required.

We believe the LMA, used in conjunction with a shroat pack (as described above), Moffett's Solution to minimize mucosal bleeding and simultaneous irrigation and aspiration, is a sofe technique for nasal surgery.

P.J. Williams BM FRCA

Department of Anaesthesia

Lewisham Hospital

Lewisham High Street

London SE13 6LH

P.M. Bailey MB RS FRCA

Department of Anaesthesia

The Royal National Throat, Nose \& Ear Hospital

Gray's Inn Road

London WC1X 8DA
REFERENCES

1 Fisher $J A$, Ananthanarayan $C$, Edelist $G$. Role of the laryngeal mask in airway management. Can J Anaesth 1992; 39: 1-3.

2 Williams PJ, Bailey PM. Comparison of the reinforced laryngeal mask airway and tracheal intubation for adenotonsillectomy. Br J Anaesth 1993; 70: 30-3.

3 Brain AIJ. Three cases of difficult intubation overcome by the laryngeal mask air way. Anaesthesia 1985; 40: 353-5.

4 Beveridge $M E$. Laryngeal mask anaesthesia for cleft palate. Araesthesia 1989; 44: 656-7.

5 Heath $M L$, Allagain $J$. Intubations through the laryngeal mask. Anaesthesia 1991; 46: 545-8.

\section{The laryngeal mask airway and ocular injury}

To the Editor:

The laryngeal mask airway (LMA) has already been documented for use on ophthalmic surgery ${ }^{1}$ but not for ocular injury. A case is presented where an LMA was used to avoid the risk of further trauma to the eyes of a patient who had sustained bilateral penetrating eye injuries and required surgical treatment.

A 32-yr-old woman presented with bilateral perforating eye injuries. She had multiple lacerations and bruising of her face. Her left upper eyelid was lacerated exposing the proptosed eye-ball (Figure). On arrival in the anaesthetic room she was unpremedicated and starved. The patient was monitored with a pulse oximeter and preoxygenated. Anaesthesia was induced with thiopentone $225 \mathrm{mg}$, and alfentanil $1 \mathrm{mg}$ which rendered the patient apnoeic. An airtight seal could not be attained with the

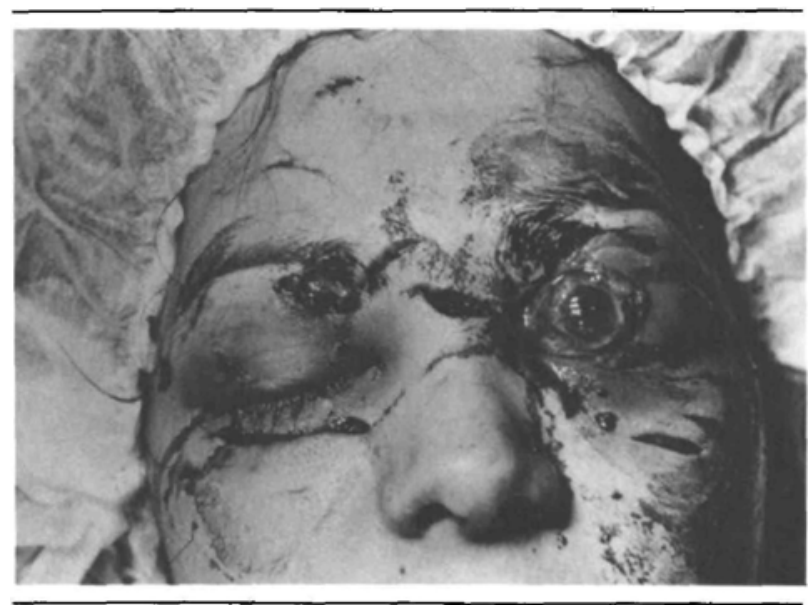

FIGURE Ocular injuries sustained including proptosis of the left eye. 